\title{
Failure to Capture
}

National Cancer Institute

\section{Source}

National Cancer Institute. Failure to Capture. NCI Thesaurus. Code C62993.

Problem associated with the failure to achieve effective and consistent depolarization of the heart resulting from the electrical stimulus of the pacemaker. 